\title{
Prevalence of COVID-19 diagnosis in Dutch CML patients during the 2020 SARS-CoV2 pandemic. A prospective cohort study
}

\author{
Geneviève I. C. G. Ector $\mathbb{D}^{1} \cdot$ Elisabeth G. W. Huijskens ${ }^{2} \cdot$ Nicole M. A. Blijlevens $^{1} \cdot$ Peter E. Westerweel ${ }^{3}$
}

Received: 19 June 2020 / Revised: 26 June 2020 / Accepted: 1 July 2020 / Published online: 8 July 2020

(c) Springer Nature Limited 2020

\section{To the Editor:}

We read with interest the article by $\mathrm{Li}$ et al. first to report on COVID-19 in patients with chronic myeloid leukaemia (CML) [1]. They found an increased COVID-19 prevalence in CML patients of the Hubei region in China when compared to the prevalence of the general population of that region. Unfortunately, in this retrospective study, follow-up data were not provided and a direct control group was not included.

We report preliminary results of a prospective Dutch observational cohort study that assessed differences in susceptibility for COVID-19 and severity of the disease course in adult CML patients and their adult housemates during the SARS-CoV2 pandemic (the first COVID-19 case was identified on February 27th in the Netherlands). Patients were invited to participate via CMyLife [2], a nationwide web-based portal focused on Dutch CML patients, from April 6th 2020 onwards. If available, their adult housemates (e.g., spouses) were included as control group, providing a better representation of the general population.

Surveys were performed at baseline and at a 2-weekly follow-up period. CML patients receiving TKI treatment or having a discontinuation of their TKI treatment were invited to participate. The study was approved by the Radboudumc institutional ethics committee and digital informed consent was obtained from both patients and partners.

Supplementary information The online version of this article (https:// doi.org/10.1038/s41375-020-0964-0) contains supplementary material, which is available to authorized users.

Geneviève I. C. G. Ector

genevieve.ector@radboudumc.nl

1 Department of Haematology, Radboud University Medical Centre, Nijmegen, The Netherlands

2 Department of Clinical Microbiology, Albert Schweitzer Hospital, Dordrecht, The Netherlands

3 Department of Haematology, Albert Schweitzer Hospital, Dordrecht, The Netherlands
At inclusion, information was gathered on demographics, self-reported comorbidity, vaccinations, health rating, COVID-19 related symptoms and hospital admissions and additional for patients; CML course, patients' perceptions regarding CML and COVID-19. Every 2 weeks a truncated shorter version of the questionnaire was conducted, focusing on TKI intake, preventive measures, testing, symptoms and hospital admissions.

At time of submission, 167 patients have registered for the study and $148 \mathrm{CML}$ patients (median age, 57.5 years; range 26-82 years; $48 \%$ males) and 123 housemates (median age 60 years, range 24-88 years) were included, with enrolment still ongoing. The baseline characteristics are presented in Supplementary Table 1 . The majority (88.4\%) had taken TKI therapy.

Approximately half of the CML patients versus a third of controls had comorbidity that required medication. The annual influenza vaccination was received by $58.0 \%$ of the CML patients and $35.8 \%$ of their housemates. If a coronavirus vaccine would become available, both patients and their housemates would be largely willing to take this (76.3\% and $68.9 \%$, respectively). The majority applied preventive measures as recommended by national institutes (e.g., not shaking hands, frequently washing hands and social distancing). Patients' perceptions regarding COVID19 are shown in Table 1.

Next we analysed symptoms of patients and housemates at inclusion (Table 2). Among patients, rhinitis was the most reported symptom (16.9\%), followed by coughing (14.2\%) and dyspnoea (10.8\%). Fever was not reported. Many (69.6\%) patients reported to be symptom free. Among the housemates, rhinitis was reported in $8.9 \%$ of cases, and coughing and dyspnoea in $6.5 \%$ and $2.4 \%$, respectively. Again, fever was not reported. The majority (84.6\%) reported to be free of symptoms. Only two patients had been tested for SARS-CoV2 at study inclusion, of whom one tested positive and reported to have been admitted to the hospital (without ICU admission). This patient was a 62 year male without comorbidity, who received imatinib therapy since the CML 
Table 1 Reported perceptions of patients on COVID-19 related to CML.

Patients $(N=148)$

$\%(n)$

Thinks to be more susceptible to COVID-19 because of CML

$\begin{array}{ll}\text { Yes } & 32.4(48) \\ \text { No } & 35.8(53) \\ \text { Do not know } & 31.8(47)\end{array}$

Thinks COVID-19 course will be more severe due to CML

Yes

$35.8(53)$

No

$20.3(30)$

Do not know

$43.9(65)$

Worries about the coronavirus

Not at all

$5.4(8)$

A little

$54.7(81)$

Quite a bit

$30.4(45)$

Very much

$9.5(14)$

diagnosis 2 years before. No housemates were tested nor reported any hospital admissions.

Currently, most subjects have completed their first and second 2-weekly follow-up questionnaires (Supplementary Table 2). No patients reported (temporarily) TKI discontinuation. A further six persons (two patients and four housemates) were tested for SARS-CoV2 during this follow-up and all tested negative. No hospital admissions were reported. At 2 weeks, 74.2\% $(n=95)$ of the patients reported to be free of symptoms, compared to $79.4 \%$ ( $n=$ $100)$ and $88.9 \%(n=16)$ at four and 6 weeks, respectively. For housemates these rates were $87.6 \%(n=106), 91.6 \%$ $(n=98)$ and $100 \%(n=15)$, respectively.

To conclude, we found no significantly increased prevalence of COVID-19 in CML patients. Only one patient $(0.7 \%)$ reported to be tested positive and has been admitted to the hospital. These findings are important for CML patients and professionals (prescribers of TKI) as almost $40 \%$ of patients reported to be substantially concerned about the coronavirus. The prevalence rate is in line with the reported $0.3 \%$ in the general Dutch population [3], and with the reported low prevalence of $<1 \%$ SARS-CoV2 viral infections in CML patients in the study of $\mathrm{Li}$ et al. We included a representative control cohort of housemates of similar age and geographical spreading as the patients, of whom none were tested positive $(0 \%)$. Similar to $\mathrm{Li}$ et al. $(0.9 \%$ vs $0.1 \%)$, we did find a slightly higher percentage of infected patients than in the general population $(0.7 \%$ vs $0.3 \%$ ) based on PCR testing on clinical indication, but this is not statistically significant. Other studies focusing primarily on COVID-19 infection prevalence in CML population are lacking.
Table 2 Information on preventive measures, symptoms and hospital admissions related to COVID-19 in CML patients at inclusion.

\begin{tabular}{|c|c|c|}
\hline & $\begin{array}{l}\text { Patients } \\
(N=148) \\
\%(n)\end{array}$ & $\begin{array}{l}\text { Housemates } \\
(N=124) \\
\%(n)\end{array}$ \\
\hline Visited affected area ${ }^{a}$ & $3.4(5)$ & $4.1(5)$ \\
\hline \multicolumn{3}{|l|}{ Preventive measures $^{\mathrm{b}}$} \\
\hline None & 0 & N/A \\
\hline Avoid shaking hands & $85.1(126)$ & N/A \\
\hline Clean hands often & $84.5(125)$ & N/A \\
\hline Use of face mask & $2.7(4)$ & N/A \\
\hline $\begin{array}{l}\text { Working from home, just as } \\
\text { same-function colleagues }\end{array}$ & $31.8(47)$ & N/A \\
\hline $\begin{array}{l}\text { Working from home, in } \\
\text { contrary to same-function } \\
\text { colleagues }\end{array}$ & $6.8(10)$ & N/A \\
\hline Self-isolation & $41.2(61)$ & N/A \\
\hline Other & $14.9(22)$ & N/A \\
\hline \multicolumn{3}{|l|}{ Symptoms ${ }^{\mathrm{b}}$} \\
\hline Rhinitis & $16.9(25)$ & $8.9(11)$ \\
\hline Coughing & $14.2(21)$ & $6.5(8)$ \\
\hline Sore throat & $4.1(6)$ & $2.4(3)$ \\
\hline Dyspnoea & $10.8(16)$ & $2.4(3)$ \\
\hline Fever & $0(0)$ & $0(0)$ \\
\hline No symptoms & $69.6(103)$ & $84.6(104)$ \\
\hline \multicolumn{3}{|l|}{ SARS-CoV2 testing } \\
\hline Tested, positive & $0.7(1)$ & 0.0 \\
\hline Tested, negative & $0.7(1)$ & 0.0 \\
\hline Not tested & $98.0(145)$ & $100(123)$ \\
\hline Unknown & $0.7(1)$ & 0 \\
\hline Hospital admission $^{c}$ & $0.7(1)$ & $0.0(0)$ \\
\hline $\begin{array}{l}\text { Intensive Care Unit } \\
\text { admission }\end{array}$ & $0.0(0)$ & $0.0(0)$ \\
\hline \multirow[t]{2}{*}{ Lives with adult housemate } & $85.9(128)$ & - \\
\hline & $\begin{array}{l}N=131 \\
\%(n)\end{array}$ & $\begin{array}{l}N=106 \\
\%(n)\end{array}$ \\
\hline
\end{tabular}

Vaccines

Annual influenza vaccination

$\begin{array}{lll}\text { Yes } & 58.0(76) & 35.8(38) \\ \text { No } & 42.0(55) & 64.1(68)\end{array}$

If available, would take corona vaccine

$\begin{array}{lcc}\text { Yes } & 76.3(100) & 68.9(73) \\ \text { No } & 3.8(5) & 0.9(1) \\ \text { Do not know } & 19.8(26) & 30.2(32)\end{array}$

${ }^{\text {a} A f f e c t e d ~ a r e a s ~ w i t h ~ h i g h ~ r i s k ~ o f ~ C O V I D-19 ~ a s ~ e s t a b l i s h e d ~ b y ~}$ National Institute for Public Health and the Environment: Italy, Austria, Nordrhein Westfalen (Germany), Madrid (Spain), China, South Korea, Iran.

${ }^{\mathrm{b}}$ Multiple answers possible.

${ }^{\mathrm{c}} \mathrm{Hospital} / \mathrm{ICU}$ admission because of the following symptoms: coughing, dyspnoea and/or fever. 
There are strengths and limitations to our study. Although there may have been some self-selection bias in our study, the recruitment through the national CMyLife digital patient platform did allow for a substantial and geographically nationwide spread of participants, also in a time when many patients isolated themselves and hospital visits were limited when possible. Also, our study was performed prospectively, and included a control group. Furthermore, our questionnaires focused on patients' perceptions, offering insights in the substantial level of anxiety in this patient group. However, the number of SARS-CoV2 tested subjects was low, limiting statistical power.

Taken together, the report by $\mathrm{Li}$ et al. and our current data may offer relief to CML patients in general that the absolute risk of contracting a serious SARS-CoV2 infection in CML patients, was low $(<1 \%)$ during the COVID-19 pandemic. However, as we did observe more upper airway symptoms and further research should focus on serological testing in the CML population to objectively assess subclinical COVID-19 infection prevalence. Finally, our study supports that patients can safely continue their TKI.
Author contributions GICGE and PEW designed the study; GICGE analysed the data; GICGE wrote the paper with contributions from all authors, who also interpreted the data, and read, commented on and approved the final version of the paper.

\section{Compliance with ethical standards}

Conflict of interest The authors declare that they have no conflict of interest.

Publisher's note Springer Nature remains neutral with regard to jurisdictional claims in published maps and institutional affiliations.

\section{References}

1. Li W, Wang D, Guo J, Yuan G, Yang Z, Gale RP, et al. COVID-19 in persons with chronic myeloid leukaemia. Leukemia. 2020:1-6.

2. Ector GI, Westerweel PE, Hermens RP, Braspenning KA, Heeren BC, Vinck OM, et al. The development of a web-based, patientcentered intervention for patients with chronic myeloid leukemia (CMyLife): design thinking development approach. J Med Internet Res. 2020;22:e15895.

3. Epidemiologische situatie COVID-19 Nederland 03-06-2020. Bron: Rijksinstituut voor Volksgezondheid en Milieu (RIVM); 2020. https://www.rivm.nl/documenten/epidemiologische-situatiecovid-19-in-nederland-3-juni-2020. 